\title{
Formation of the freight trains with a fixed train schedule
}

\author{
Aleksandr Svetashev ${ }^{*}$, Shokhrukh Kamaletdinov, Nargiza Svetasheva and Guldora \\ Mustaeva \\ Tashkent State Transport University, Tashkent, Uzbekistan
}

\begin{abstract}
The hypothesis of the study consists of the detailed consideration of the process of accumulation of wagons, taking into account the arrival of individual groups of wagons, determination of options for freight trains with a fixed train schedule and substantiation of analytical dependencies that determine the cost of wagon-hours for accumulating trains and obtaining new scientific results on this basis. Their practical use will make it possible to more accurately and reasonably normalize the idle time of cars under accumulation, as well as to clarify the methodology for calculating the train formation plan. The research methodology is based on existing methods and methods of forming freight trains for a rational way of implementing the train schedule. Results of the study: the methods of standardizing the idle time of cars under accumulation were stated, the regulations of idleness of cars at the sorting yard were clarified, and options for optimizing the plan for the formation of trains were proposed.
\end{abstract}

\section{Introduction}

One of the most important and complex processes for arranging cars is forming freight trains. The car traffic entering the sorting yard is transformed into an outgoing one by disbanding arriving trains, accumulating trains and forming new trains following the formation plan. The main and most difficult element of the formation of freight trains is the process of accumulating wagons. However, operational science has developed a simplified approach to considering this process and substantiating its parameters, which indicates the need for further development of the theory of train formation.

A study looked through the relationship and capacity of sorting devices with the station's capacity and their impact on wagon downtime. Viewed the station as an important aspect of rail connectivity and that the station affects overall traffic satisfaction and the impact of wagon downtime under accumulation. The main accidents associated with the temporary storage of hazardous substances in the transport industry are examined. In particular, the dangers associated with the presence of hazardous substances in port areas and the sorting of wagons and cargo. The article presents a new approach to the development and management of a new sorting yard, which will lead to the increase in the

\footnotetext{
*Corresponding author: aleksandr-svetashev@bk.ru
} 
efficiency of all sorting yard operability systems and accelerate freight delivery by automating and optimizing certain processes. The work considered multimodal transportation that can be economical and environmentally friendly. Complex transport processes require planning network flows and developing models at a tactical level, covering several stages and routes of the multimodal network to determine the minimum costs of accumulation, tracing and reliability of operations. The study considers the multistage formation of trains on mixed tracks of the sorting yard; a comprehensive review of the sorting yard operation showed that it is possible to use more efficient train schedules by optimizing many characteristics, including shunting work. The work considers the problem of passing trains through railway stations. The development involves the necessary ways to increase the capacity of both stations and the railway infrastructure of the Netherlands in general. The article considers the problems of forming trains at sorting yards and analyzes the patterns of forming freight trains. At freight stations, the most common problems arise in the management of personnel, goods and infrastructure. The main issue is to reduce the downtime of cars at the train formation station. In the article, he proposed using a software product to control the operation of sorting devices for the rapid and safe formation of trains. In his dissertation research, he proposes an operational planning strategy that will help find a cost-effective wagon sorting schedule and shunting dispatcher, which will reduce the accumulated wagon downtime. The article discusses the optimization of the train formation plan, which considers the combination of single-group trains with multi-group ones. That will reduce the time of delivery of goods and reduce the idle time of the carriage hours under the accumulation of trains. In works, an algorithm is presented that allows you to significantly save time for the formation of trains and reduce its cost by solving problems related to the timely and rational formation of trains, in the context the class of stations is given, and a systematic approach is presented that allows a more accurate division of work between these stations. The articles presented the development of an operational plan for organizing the work of a sorting yard, which in turn optimized production capacity, and also developed a model to minimize the average idle time of cars under accumulation. Presents new methods of forming freight trains at stations and also suggests ways to improve the quality of station operation. Identified various transport hubs, presented the potential needs of railway stations and their interactions with other modes of transport.

\section{Methods}

In accordance with this, the purpose of this study is to substantiate the varieties of the formation of trains at sorting yards and the parameters characterizing it, as well as the dependencies that determine these parameters and the cost of car-hours for the accumulation of cars. To achieve this goal, it is necessary to solve the following tasks:

- justification of options for the formation of trains;

- study of the parameters of the trains formation at the sorting yards using a fixed schedule for the accumulation of cars and justification of methods for calculating the average daily costs of car-hours for the accumulation of trains;

- development of a simulation model of options for the formation of trains for individual assignments of the formation plan to check the reliability of the established analytical dependencies and justify the values of parameters that cannot be analytically determined;

- justification of the conditions for the use of options for the formation of trains.

The analysis showed that there are various options for the formation of trains at marshalling yards of railways in the 1520 gauge area. In this case, the feature of the accumulation of cars is determined by two factors: the method of rationing the number of 
cars in the formed trains (train norms) and the method of implementing the traffic schedule for the departure of the formed trains.

The formation of a train is understood as a system that combines the process of accumulating wagons for train sets and a way of operating the schedule for these trains. It is an accumulation of trains up to a certain point in time established by the train schedule, while the length of the formed trains should not go beyond the established range - the norm of the trains on a fixed schedule.

The most effective way to implement the train schedule is to use it according to the principles of a fixed schedule, i.e. the departure of trains of a certain purpose every day at the same time and their operating along the interconnected schedule threads throughout the route. Therefore, a detailed study of this issue and the determination of the conditions for the possible use of a fixed schedule for the movement at technical routes when forming them at marshalling yards is of significant scientific and practical interest.

Due to the uneven arrival of wagons, it is impossible to ensure the accumulation of all trains to the maximum train norm with a fixed schedule. Therefore, the average value of trains $m$ will be less than the maximum allowed track capacity $m_{\max }$ for a certain number of cars $\Delta m$. The minimum possible dimensions of movement are determined by the average daily car traffic for a given destination $U_{c y m}$ and by the maximum size of the train (fixed norm) $m_{\max }$.

$$
N_{\min }=\frac{U_{\mathrm{cyr}}}{m_{\max }} \text { trains }
$$

The length of the train movement that can be put down in a fixed schedule is determined by rounding $N_{\min }$ up

$$
N_{\text {гр }}=\left|N_{\min }\right|+1 \text { trains }
$$

where $\left|N_{\text {min }}\right|$ is the integer part of the value $N_{\text {min }}$, trains.

Then the average calculated value of the train with a fixed schedule will be

$$
m=\frac{U_{\text {cyт }}}{N_{\text {rp }}} \text { wagon }
$$

and the deviation from the maximum permissible value

$$
\Delta m=m_{\max }-m \text { wagon }
$$

the minimum allowed length of the train will be $m_{\min }=m-\Delta m$, wagon.

Thus, the actual number of wagons in the formed trains $m_{\phi}$ can vary in the range from $m_{\min }$ to $m_{\max }$ of wagons: $(m-\Delta m) \leq m \leq(m \pm \Delta m)$.

If the number of wagons accumulated per train exceeds $m_{\max }$, then the excess goes to the remainder and participates in the accumulation of the next train. If the number of accumulated wagons are less than $m_{\min }$, then the train is cancelled, and these wagons in the form of a remainder are transferred to the accumulation of the next train. When the remainder grows, and its value approaches the $m_{\max }$ value, an additional train is assigned.

Cancellation and appointing of trains reduce the percentage of meeting fixed schedules. On the other hand, the remainder of the cancelled train is distributed over the accumulation of other trains, increasing the size of their trains and increasing its average value from the calculated $m$ to the actual $m_{\phi}$. In the absence of cancellations and appointments of trains, a full (one hundred per cent) fixed schedule is implemented, if any, an incomplete fixed schedule, the quality of which is characterized by the established percentage of its completion. 
Thus, we can distinguish the following features of the process of accumulating cars with a fixed schedule:

1. The end of the accumulation of a train is determined not by the number of wagons entering the accumulation track but by the fixed departure time of the train.

2. For each train appointment, the possible deviation $\Delta m$ from the average value of the train up and down is uniquely determined.

3 . The average value of the closing group is equal to the average value of the incoming group.

4. The need in some cases of cancellation of scheduled and appointment of additional trains.

5. Since the moment of the end of the accumulation of trains is strictly fixed, there may be cases of earlier accumulation of trains. In these cases, there is a downtime of the accumulated trains either in the sorting yard or in the departure yard.

Let us consider a detailed averaged graph of the accumulation of cars with a fixed schedule of train traffic (Figure 1).

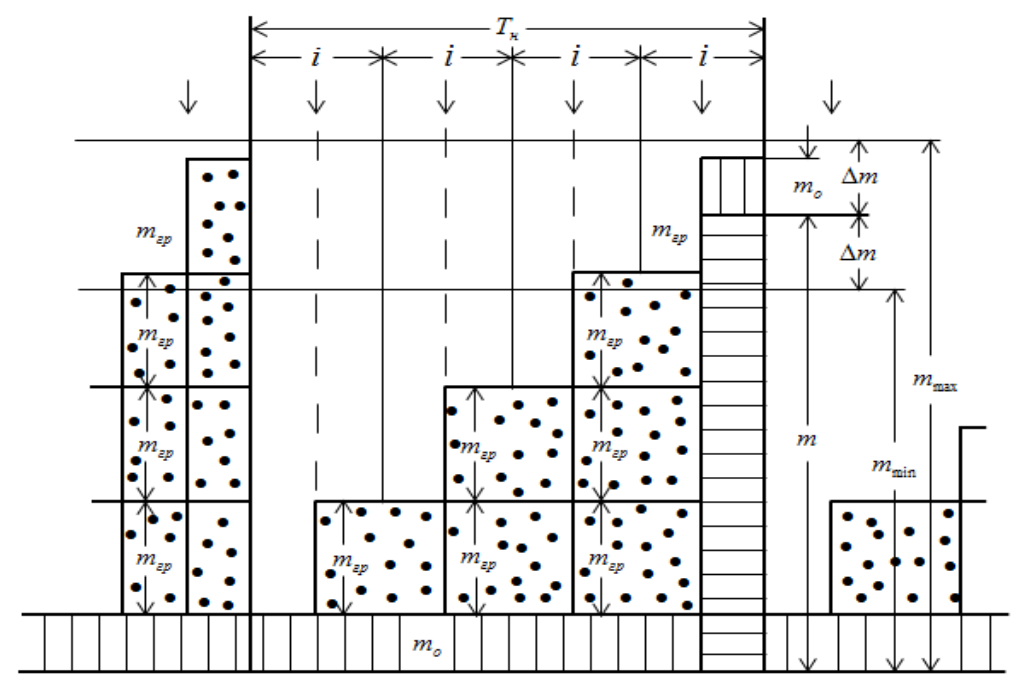

Fig.1. Graphical diagram of the accumulation of the train in a fixed schedule

The average value of the remainder of wagons is determined by the expression

$$
m_{\mathrm{o}}=\frac{\sum u t_{o}}{24}
$$

where $\sum u t_{o}$ is average daily wagon-hours spent on accumulating balances; $\Delta m$ is the limiting value of possible deviations of the actual number of wagons in the accumulated trains from the average value of the train size $m, \Delta m=m_{\max }-m ; m_{2 p}$ is average value of the incoming group of cars; $i$ is average arrival interval of car groups; $T_{H}$ is average train accumulation period; $m_{\max }, m_{\min }$ are respectively the maximum and minimum possible length of the trains.

There is no downtime of the accumulated train if the moment of arrival of the last group of cars coincides with the moment of the end of accumulation, i.e., at the moment of the end of the last interval of the arrival of groups $i$. The maximum idle time of the accumulated train will be in the case of the arrival of the last group of cars at the beginning of the last interval of the arrival of groups $i$. The average idle time of the accumulated train will be equal to $0,5 i$, and the cost of a wagon -hours of idle time on average per day 


$$
B_{c}=0.5 \cdot i \cdot m \cdot N_{\text {гр }}^{\phi}=0.5 \frac{\mathrm{T}_{\mathrm{H}}}{n} m \cdot N_{\text {гр }}^{\phi}=0.5 \frac{24 \cdot m_{\mathrm{гр}}}{N_{\text {гр }}^{\phi} \cdot m} m \cdot N_{\text {гр }}^{\phi}=12 m_{\text {гр }}
$$

Downtime under the accumulation of incoming groups of cars is determined by $B_{\text {cp }}=12\left(m-m_{\text {cp }}\right)$.

Downtime of the remainder of wagons $B_{o}=24 m_{o}$.

Then the total average daily cost of car-hours for accumulation, taking into account the idle time of the accumulated trains, will be $B=B_{z p}+B_{c}+B_{o}=12\left(m-m_{r p}\right)+12 m_{r p}+24 m_{o}$, or

$$
\begin{aligned}
& B=12\left(m+2 m_{o}\right) \\
& c=12\left(1+\frac{2 m_{o}}{m}\right)
\end{aligned}
$$

The considered graph reflects the situation when the number of cars accumulated per train falls within the range. In the real process of forming trains, there will be cases when this number of wagons goes beyond the specified limits. If the upper limit is exceeded, $m_{H}>m_{\max }=m-\Delta m$, the remainder of the cars is formed. If the number of accumulated cars does not reach the lower limit $m_{H}<m_{\min }=m-\Delta m$, then the formation of the train is cancelled, and all these cars are transferred to the remainder, which is subsequently either absorbed by the accumulated trains increasing them up to $m_{\max }$, or with an intensive approach of cars increases to such an extent that it becomes necessary to appoint additional non-scheduled trains. In this case, there is an incomplete fixed schedule, the quality of which can be assessed by the percentage of completion of the fixed schedule.

\section{Results and Discussion}

As a result of modelling the formation of trains for each purpose, the following parameters were established:

- actual average train length value $m_{\phi}$ :

$$
m_{\phi}=\frac{U}{N_{\phi}} \text { wagon }
$$

where $U$ is average daily wagon-flow; $N_{\phi}$ - average daily total number of trains dispatched $\left(N_{\phi}=N_{z p}+N_{\text {доn }}\right)$.

- actual mean deviation $\Delta m_{\phi}$ :

$$
\Delta m_{\phi}=m_{\max }-m_{\phi}
$$

- average value of wagon remainder $m_{o}$ :

$$
m_{o}=\frac{\sum u t_{o}}{24} \text { wagon. }
$$

where $\sum u t_{o}$ is average daily cost of wagon-hours accumulating the remainder of wagons.

- average daily cost of accumulation $B$ :

$$
B=12\left(m_{\phi}+2 m_{o}\right)
$$

- average value of the accumulation parameter $c$ : 


$$
c=12\left(1+\frac{2 m_{o}}{m}\right)
$$

Simulation of the train formation process showed a large range of the remainder values of the cars at the same $\gamma$ value. The percentage of trains departing on a fixed schedule for the considered destinations was in the range from 70 to $99 \%$. This suggests that marshalling yards are characterized by an incomplete fixed schedule caused by the cancellation of scheduled trains when the train accumulates less than the lower limit of the permissible range $\left(m_{\text {нак }}<m_{\text {min }}\right)$.

The data analysis analysis made it possible to establish the dependence $m_{o}=f(\gamma)$ as a straight line $m_{o}=22.604 \gamma-11.983$ (Figure 2), which can be used to analytically determine the approximate value of the average residue. The value of $\gamma_{\phi}$ can be determined by the established stable function $\gamma_{\phi}=1.20 \gamma-0.08$.

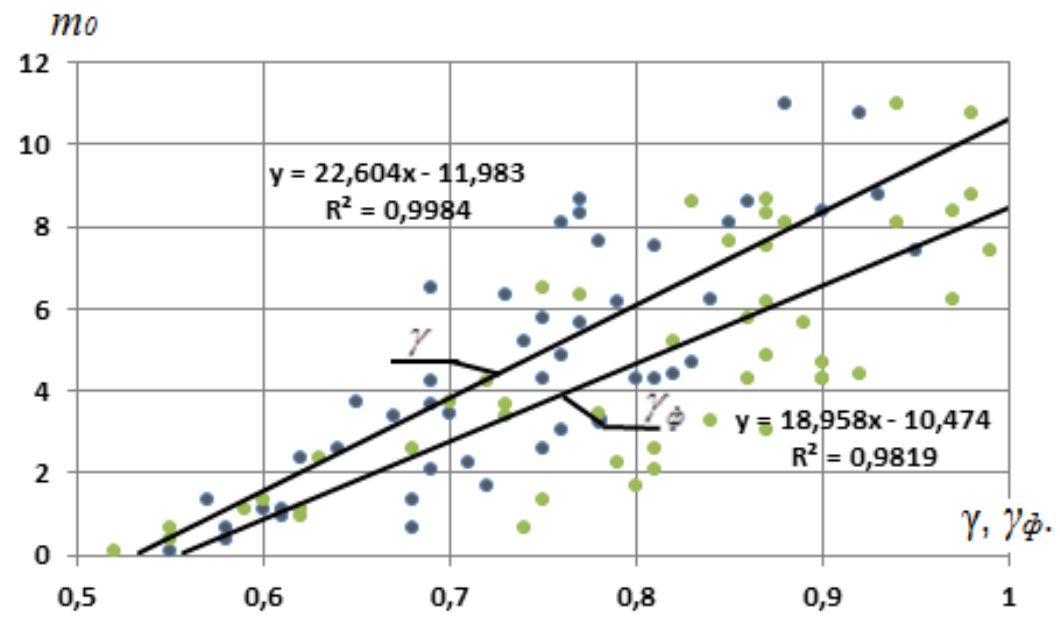

Fig.2. Graph of dependence of the remainder of cars on $\gamma$ and $\gamma_{\phi}$.

The value of $\gamma_{\phi}$ should be used when choosing the appointments of the formation plan for a fixed train schedule. Due to the wide range of the averaged values of the remainder of the cars, the daily costs of the car-hours for the accumulation of cars are expedient to calculate according to the formula (9), using the statistically established actual values of $m_{\phi}, m_{z p}$ and $m_{o}$.

\section{Conclusions}

Thus, to move to a fixed schedule, it is necessary to select the most powerful and stable wagon flows at sorting yards following the recommended values, identify the lines of the fixed schedule and coordinate their schedule along the entire route. Gradually master the fixed schedule, conduct a thorough analysis of wagon traffic, take them into account when calculating the formation plan and link them to the train schedule.

The established analytical dependences make it possible to determine the average value of the remainder of the wagons for the considered options for implementing the traffic schedule without processing statistical studies and modelling the train formation, the accounting of which will contribute to a more reasonable determination of the average daily costs of car-hours for accumulation and the accumulation parameter of cars. 
The use of the fixed schedule will allow: to avoid the guaranteed absence of all delays and overlaps, regularity and guarantee of the arrival date, the ability of locomotive crews to work according to personal schedules, simplification of operational planning, etc. These features determine the prospects of this method of operating the schedule.

\section{References}

1. Armstrong $\mathrm{J}$ and Preston $\mathrm{J}$, Capacity utilization and performance at railway stations Journal of Rail Transport Planning \& Management. 7. (3) pp 187205. doi:10.1016/j.jrtpm.2017.08.003, (2017).

2. Brons $M$, Givoni $M$ and Rietveld $P$, Access to railway stations and its potential in increasing rail use Transportation Research Part A, Policy and Practice. 43. (2) pp 136-149. doi:10.1016/j.tra.2008.08.002, (2009).

3. Christou M, Analysis and control of major accidents from the intermediate temporary storage of dangerous substances in sorting yards and port areas, Journal of Loss Prevention in the Process Industries 12 (1) pp 109-119. doi:10.1016/s09504230(98)00043-6. (1999).

4. Dimitrov L, Purgic S, Tomov P and Todorova M, Approach for Development of Real-Time Sorting Yard Management System, 2018 International Conference on High Technology for Sustainable Development (HiTech). doi:10.1109/hitech.2018.8566369, (2018).

5. Elbert R, Müller $J$ and Rentschler $J$, Tactical network planning and design in multimodal transportation - A systematic literature review, Research in Transportation Business \& Management 100462. doi:10.1016/j.rtbm.2020.100462, (2020)

6. Gestrelius S, Aronsson M, Joborn M and Bohlin M, Towards a comprehensive model for track allocation and roll-time scheduling at sorting yards, Journal of Rail Transport Planning \& Management 7. (3). pp 157170. doi:10.1016/j.jrtpm.2017.06.002 . (2017).

7. He S, Song R and Chaudhry S, An integrated dispatching model for rail yards operations, Computers \& Operations Research 30 (7) 939-966. doi:10.1016/s03050548(02)00064-3, (2003).

8. Kroon L, Edwin Romeijn $\mathrm{H}$ and Zwaneveld $\mathrm{P}$, Routing trains through railway stations: complexity issues, European Journal of Operational Research 98. (3). pp 485-498. doi:10.1016/s0377-2217(95)00342-8. (1997).

9. Lin B and Zhao Y 2019 The Systematic Optimization of Train Formation in Loading Stations Symmetry 11(10) 1238. doi:10.3390/sym11101238

10. Peng W and Lin Z, Research on Risk Assessment of Railway Freight Station Based on Nonlinear Combination of Ahp-Entropy, 2018 15th International Conference on Service Systems and Service Management (ICSSSM). doi:10.1109/icsssm.2018.8465075. (2018).

11. Rietveld P, The accessibility of railway stations: the role of the bicycle in The Netherlands Transportation Research Part D, Transport and Environment 5 (1) pp 71-75. doi:10.1016/s1361-9209(99)00019-x. (2000).

12. Shrivastav $\mathrm{P}$ and Dhingra S, Development of Feeder Routes for Suburban Railway Stations Using Heuristic Approach, Journal of Transportation Engineering 127 (4) pp 334-341. doi:10.1061/(asce)0733-947x(2001)127:4(334). (2001).

13. Xiao $\mathrm{J}$ and Lin B, Comprehensive optimization of the one-block and two-block train formation plan, Journal of Rail Transport Planning \& Management 6,(3). pp 218 236. doi:10.1016/j.jrtpm.2016.09.002. (2016). 
14. Xiao J Lin B and Wang J, Solving the train formation plan network problem of the single-block train and two-block train using a hybrid algorithm of genetic algorithm and tabu search, Transportation Research Part C: Emerging Technologies, 86, pp 124-146.doi:10.1016/j.trc.2017.10.006. (2018).

15. Yaghini $M$ Momeni $M$ and Sarmadi $M$, Solving train formation problem using simulated annealing algorithm in a simplex framework, Journal of Advanced Transportation 48. (5). pp 402-416.doi:10.1002/atr.1183.( 2012).

16. Yaghini M Momeni $M$ and Sarmadi $M$, An improved local branching approach for train formation planning, Applied Mathematical Modelling 37, (4), pp 23002307. doi:10.1016/j.apm.2012.05.016. (2013)

17. Yaghini M Momeni M and Sarmadi M, A hybrid solution method for fuzzy train formation planning, Applied Soft Computing 31 pp 257265. doi:10.1016/j.asoc.2015.02.039. (2015).

18. Zemp S Stauffacher M Lang D J and Scholz R, Classifying railway stations for strategic transport and land use planning, Context matters! Journal of Transport Geography 19 (4) pp 670-679. doi:10.1016/j.jtrangeo.2010.08.008, (2011).

19. Zhou W Tian J Deng L and Qin J. Integrated Optimization of Service-Oriented Train Plan and Schedule on Intercity Rail Network with Varying Demand, Discrete Dynamics in Nature and Society, pp 1-9. doi:10.1155/2015/419042. (2015).

20. Zhou W Yang X Qin J and Deng L. Optimizing the Long-Term Operating Plan of Railway Sorting Station for Capacity Utilization Analysis, The Scientific World Journal 2014, 1-13. doi:10.1155/2014/251315. (2014). 